\title{
The Experience, Impact, and Management of Professional Burnout Among Probation Officers in Juvenile Justice Settings
}

\author{
Michelle P. Salyers, PhD \\ Associate Professor, Department of Psychology, Indiana University Purdue University \\ Indianapolis (IUPUI); Co-Director, ACT Center of Indiana
}

Brittany J. Hood, BS

Graduate Assistant, School of Enviornmental and Public Affairs, Indiana University Purdue University Indianapolis (IUPUI), Master's in Criminal Justice and Public Safety

Katherine Schwartz, JD, MPA

Visiting Faculty Research Associate, Section of Adolescent Medicine, Department of Pediatrics, Indiana University School of Medicine, Indianapolis, IN

Andrew O. Alexander, BS

Research Assistant, Section of Adolescent Medicine, Department of Pediatrics, Indiana University School of Medicine, Indianapolis, IN

Matthew C. Aalsma, PhD

Associate Professor, Section of Adolescent Medicine, Department of Pediatrics, Indiana University School of Medicine, Indianapolis, IN

Address correspondence to:

Michelle P. Salyers, Ph.D.

Department of Psychology, LD 124

402 N. Blackford St.

Indianapolis, IN 46202

Tel: (317) 274-2904; Fax: (317) 274-6756; Email: mpsalyer@iupui.edu

Acknowledgements: This study is funded by grants from the Indiana Criminal Justice Institute and R40 MC 08721, through the U.S. Department of Health and Human Services, Health Resources and Services Administration, Maternal and Child Health Research Program and the Indiana Criminal Justice Institute. 


\begin{abstract}
Little is known about the experience of professional burnout among juvenile probation officers. Following a state-wide survey, 26 officers were randomly selected for qualitative interviews. Using emergent, consensus-based methods, we identified key aspects of the burnout experience. Officers described burnout in ways consistent with research definitions. Most probation officers identified negative effects of burnout, including spending less time getting to know the clients and becoming more directive. Probation officers tended to have limited strategies for managing burnout. Given the important role probation officers play in the lives of juvenile justice involved youth, more work is needed to help ameliorate burnout.
\end{abstract}

The Experience, Impact, and Management of Professional Burnout Among Probation Officers in Juvenile Justice Settings 
Professional burnout has long been identified as a potential problem among probation officers (Whitehead, 1985). Yet, with a few recent exceptions (Gayman \& Bradley, 2012; Lewis, Lewis, \& Garby, 2013), little published research has appeared since the 1980s focusing on burnout in this population. Even less is known about burnout for probation officers serving juvenile justice populations (Author, under review). In general, probation officers act as extensions of law enforcement and provide supervision in the community. Probation officers with juvenile caseloads not only have a law enforcement mandate, but are also called to aid in rehabilitation (Schwalbe \& Maschi, 2009; Steiner, Purkiss, Kifer, Roberts, \& Hemmens, 2004). Given the unique responsibilities of the occupation, the purpose of the current study is to better understand the experience of burnout among juvenile probation officers.

Burnout is commonly conceptualized as feelings of emotional exhaustion, depersonalization or cynicism towards others, and reduced feelings of accomplishment or personal efficacy on the job (Maslach, 1996). Early studies of probation officers showed somewhat elevated rates of burnout compared to other human service workers, with a curvilinear pattern of lower burnout among those with the shortest and longest amount of tenure in the job (Whitehead, 1985).

Burnout in this population is not surprising given the multifaceted role of probation officers who must balance concerns of public safety, rehabilitation, and punishment of someone released from a correctional facility (Pitts, 2007). Job characteristics, such has having a high proportion of violent or sexual offenders and having experienced verbal threats or physical assault is associated with higher levels of burnout among probation officers (Lewis et al., 2013). Additionally, the number of cases that resulted in an order of probation increased dramatically between 1985 and 2009, and although may be currently declining, are still generally high (Puzzanchera, Adams, \& Hockenberry, 2012). Moreover, probation officers may have a variety of different caseload needs, ranging from youth with very minor offenses, such as status offenses, to more significant charges, such as a felony charge (Puzzanchera, Adams, \& 
Hockenberry, 2012). Thus, burnout can be attributed to or exacerbated by high number of cases with a wide variety of youth intandem with the aforementioned job characteristics.

In addition, organizational factors of the job setting, such as staffing levels and supervisor responsiveness, also contribute to burnout among probation officers (Whitehead, 1987). Recently, burnout has been shown to mediate the role between work climate/stress and depressive symptoms in probation officers (Gayman \& Bradley, 2012). This suggests that as in other occupations (Leiter \& Schaufeli, 1996; Maslach, Schaufeli, \& Leiter, 2001; Morse, Salyers, Rollins, Monroe-DeVita, \& Pfahler, 2012), burnout may have a negative impact on probation officers. Probation officers working in the juvenile justice system may be at particular risk for burnout. In addition to the usual tasks of a probation officer, juvenile workers also have potential stressors of coordinating with parents, schools, and the foster care system (Steiner et al., 2004). As stated earlier, they also have dual law enforcement and rehabilitation mandates that can be difficult to reconcile (Clear \& Latessa, 1993). In fact, it appears that probation officers who are able to synthesize both a law enforcement and rehabilitation approach are the most effective in their work (Paparozzi \& Gendreau, 2005; Skeem \& Manchak, 2008). Lastly, a study of perceived safety among juvenile probation officers found that officers exerienced threats by juveniles, although threats were more often verbal than physical (Rapp-Paglicci, 2004).

Despite burnout being a potential problem, our study team found no published studies focusing on burnout among juvenile probation officers. To address this lack of research, we recently conducted a state-wide survey of probation officers in the juvenile justice system; we found about a third scored high in burnout and that burnout was associated with lower job satisfaction and higher intentions to leave the job (Author, under review). As a supplement to that survey, we randomly selected a subsample of probation officers to interview for a better understanding of their experience of burnout. Here we report on the findings of those interviews, focusing on how juvenile probation officers define and experience burnout, how it may affect the clients they work with, and strategies they use to manage burnout. 


\section{Method}

\section{Participants}

Participants in the current qualitative study were recruited from participants in a largerscale study assessing juvenile probation officer work roles and responsibilities (Author, under review). In that study, 244 probation officers (POs) were recruited from 18 counties in a large, midwestern state. Counties were chosen based on their participation in a juvenile detentionbased mental health screening implementation project. All participants were given an online survey and were asked whether they would be willing to contribute to a follow-up phone interview (the current qualitative study) at a later date; 168 (68.9\%) POs agreed.

We sought to recruit and interview at least 30 POs for the current study. Because the 18 counties differed in substantial ways (e.g., population size, geographic location), we attempted to recruit a subsample for the qualitative study that would reflect the diversity of the PO population in the quantitative study. Therefore, of the 168 POs who agreed to be contacted, a representative number of POs were randomly selected from each county to be recruited for the current study. POs were called a maximum of three times until they were considered unreachable. Additional POs from each county were randomly selected once POs were deemed unreachable or refused participation. We contacted 60 POs by phone to reach the desired sample size; 10 POs refused to participate, 19 POs were unreachable, and 31 were interviewed. However, three interviews could not be completed; the POs began the interviews during one call but could not be reached during subsequent calls to finish. Two additional interviews were also unusable -- one for recording failure and another because the questions were deemed to be too leading (an early interview prior to corrective feedback). This resulted in a total of usable 26 interviews. Completed interviews averaged 39 minutes in length, ranging from 11 to 98 minutes over one or two phone calls. All interviews were audio-recorded and transcribed verbatim. Transcripts were de-identified and checked for accuracy. 
The final sample of probation officers was drawn from 12 counties. Of the 26 participants, $88.8 \%$ were between the ages of 40 and 59 years old. The group included 14 females (53.8\%). Most of the 26 participants were self-described as White (88.5\%), two as Black (7.7\%), and one as biracial (3.8\%). The mean length of time employed in probation was 9.2 years $(S D=5.8)$. Years spent in the juvenile justice field ranged from 6-34 years (mean = 15.8$, SD $=7.3)$. The types of caseloads supervised by the POs varied widely; $8(30.8 \%)$ participants supervised sex offenders, 14 (54\%) had high needs juveniles, 9 (35\%) managed intense supervision, and 9 (35\%) supervised pre-trial cases. Regarding caseload size, we had one outlier with 859 cases (primary caseload consisted of pretrial youth, conducting interviews with youth and their families). Removing the outlier, the average caseload was 40.6 cases (SD $=62.9)$, with a range of 0 to 257 cases.

\section{Interview Procedure}

Three undergraduate psychology research assistants conducted one semi-structured interview with each PO participant between November 2012 and April 2013. Once POs were reached via telephone, the research assistant explained the purpose and process of the study, highlighting the anonymity of their interview responses. Interviews included questions about each PO's role and length of time at the agency. By first asking an appreciative question, we prompted POs "to think of about a situation that brings out the best of who you are in your work." This was followed by questions about work engagement and burnout, including how jobrelated burnout affected them, what challenges they faced in their work, how they handled challenges, and how coworkers and clients were potentially affected by the PO's own experience of burnout. (Note: Participants were also asked a series of questions, which are not reported on here, regarding POs' assessment of their personal competency to identify and refer youth with mental health issues to appropriate care.)

Analysis and Interpretation 
A total of 26 interview transcripts were entered into Atlas-ti to be analyzed. A teambased iterative approach was used to identify themes in transcripts. Initially, the analysis team included two psychologists, two undergraduate psychology research assistants, and two fulltime research staff. First, team members independently read one to two interviews at a time, highlighting and summarizing potentially important content. Following this independent analysis, several team meetings were held to discuss individual impressions of the interviews and suggest possible codes to describe the most common interview themes. Researchers tested multiple coding systems, eliminating suggested codes that the group could not use reliably to identify a single theme. Once the final coding system was developed, two research assistants coded all interviews independently before sharing and discussing their codes with each other and reaching agreement about the primary codes present in each interview.

By consensus, the research team developed a final interview coding system composed of eight codes: 1) at your best, 2) burnout definition, 3) burnout frequency, 4) challenges, 5) managing challenges, 6) others' experiences of POs' burnout, 7) POs' burnout experience, and 8) quotable quote. The use of the "at your best" code was meant to capture times when a PO described feeling particularly engaged or enthusiastic about his or her work. Codes to gauge how POs conceptualized and perceived burnout included "burnout definition" and "burnout frequency." The "challenges" code marked any time that a PO named or described problems at work that made the job more difficult or more stressful. POs frequently indicated how they used personal skills, strategies, or colleague support to cope with job-burnout or other problems mentioned; this theme was captured with the "managing challenges" code. Two codes were designed to capture PO descriptions of the effects or consequences of burnout. When a PO described how burnout impacts him or herself, it was captured by the code "PO burnout experience." This code included descriptions of the effects of burnout on a PO's personal wellbeing as distinct from how the PO's burnout might impact personal job performance or other people at home or work. Alternatively, "others' experiences of PO burnout" was applied when a 
PO talked about how burnout affects others, whether through poor job performance, changes in mood, communication problems, and the like. This code was also used if a PO indicated that burnout did not impact others. Lastly, the "quotable quote" code was used to mark excellent passages of particularly articulate statements or concepts, surprising stories, or poignant description of events.

Following team coding of the interviews, one research assistant and one psychologist created summaries of each of the codes and compared content within and across participants. We used data display techniques, including matrices with participant IDs and columns of codes with sample quotes to better understand and describe the experience of burnout. Below we focus on how probation officers define burnout, how burnout affects their work, and how they manage burnout.

\section{Results}

\section{How do probation officers define burnout?}

In response to the question "what does burnout mean to you," the personal definition of burnout ranged on a severity continuum. At the mild end, participants described being "in a rut." As P15 shared, "Lost the passion you once had... I kinda feel like I'm in that rut now. Although I will clarify that I still do my job to the best of my ability, I still provide my clients with the level of service that they deserve, but still, I just feel like my passion for the job is diminishing. I don't enjoy it as much as I used to."

At a more severe level, participants discussed a sense of apathy and just going through the motions. For example, P1 described, "no longer caring about doing your job right. You just can't take anymore, so it becomes monotonous to do it because you have to. [You] do it to get your paycheck instead of caring or putting any effort into what you're doing." For some people, burnout incorporated a sense of "dread" - not just a lack of caring, but also feelings of avoidance, where they don't want to come to work. P2 described this sense and was careful to separate it from feelings of depression: 
I am dreading going to work every day, which is totally what I am in the middle of right now... Because, I mean, this job is terrible. I mean it is terrible, it really is terrible, it really is awful... But then occasionally a couple times a year I will be depressed at the idea of even going in there, honestly. I mean, I am definitely not depressed, but definitely on Sunday nights I, like, hate my job. I don't want to go there for another 40 hours the next week.

At the most extreme end, participants equated burnout with being "done" or "fed up," and likely to look for a new job. For example, P19 defined burnout and the consequences: "'Where I wake up and say I can't do this job one more day, one more hour. I haven't seen or experienced that personally. Obviously, if I would have felt burned out, I would have found another direction."

Out of 26 participants, 6 (23.1\%) POs said they were experiencing some level of burnout at the time of the interview, and 3 others had recently experienced it. Most individuals described burnout on the lower end of the continuum, feeling overwhelmed and less caring about their job, with a few at the "dread" or "done" stage of burnout. Several people talked about burnout as a process they deal with over time. For a few, burnout was steady, a "constant battle" (P11), such that a participant could "tell you about a time [I faced burnout] probably yesterday" (P7). For most, though, burnout appeared to wax and wane, and may reflect "peaks and valleys" (P9) over time. The more extreme forms of burnout appeared periodic:

Probably a couple times a year you just kind of want to throw your hands up and be done with it. It's [a] very, very trying type of work. Usually it passes, and I don't know if my last [period of burnout] would have probably passed as well. But when the opportunity arose [moving to a new position] I took it, but yea, I would say a couple times a year. (P1)

Similarly, P16 described, "At least once a year I go through a period of a month or two when things go particularly crazy. I'm kind of feeling that way at this point." One participant described coping with challenges over a job tenure of 15 years (P7), and that some aspects of burnout are a self-protective mechanism:

And I have four kids of my own, and if you don't dissociate yourself from this job a little bit it will drive you crazy. It will bring you down, it will drive you insane, and that's just the reality of it. So, I'm pretty good at being able to do that and I get to the point where I just don't care about my job. And that's how I live with it and deal with it. That doesn't mean I don't do my job. I just don't care about my job, and so I will go months without caring about my job very much. Now, I still think I do my job well. I just don't care about it, and 
that's how I deal with it because otherwise it would kill me....You would be hospitalized because you are going to fail so many times, or you're going to see so many heartbreaks, or you are going to see so many kids that fail. You just see bad things over, and over, and over again in this job until it would just drive you crazy, and if you allow that to happen you're gonna burnout all the time. So, I mean, if you can't just dissociate yourself from this job, you would burnout all the time. So I have mini burnouts. But real burnouts? I guess I probably really haven't any.

\section{How does burnout affect working with clients/families?}

Not sure that it does, or I don't let it. Several participants reported, when asked directly, that burnout would not impact the clients. One PO talked about her style of interaction being more focused on the task, rather than the relationship (notably, this sounds like doing the bare minimum that others describe later):

I don't know that it does necessarily. I know that might sound crazy but like I have never been a super get-involved-with-my-kids-touchy-feely type of person. We are not really encouraged to do that, which is fine because we are probation officers. I still do my job with them, I still see them, I make all my contacts with them. I regularly score fairly high on our audits and stuff like that. I am doing my work, but it's just, you know, pushing through it .... You know, I never really delve too far into their lives, I mean I just kind of do what we need to get done for court and what we need to get done with for probation. (P2)

Other participants who did not think burnout affects clients were more active in not letting burnout get in the way. They recognized that they may need to "let the stress of the day before go and try to deal with my kids." (P5) Another commented on the separation of inner and outer states: "Burnout is an inner thing that you deal with, not seen from the outside. Your image inside isn't your public image." (P17) Several talked about the work involved in separating their own stress from their interaction with clients.

Well, I think if you allow yourself to show that, you know, I think kids probably pick up on that if you're not enthusiastic. Or, if you kind of have that expectation that people are going to fail, I think they are more likely to fail. So [you] always have to try to express to them that you expect success out of them.... I've never really been burned out on that program at all. I've always been very happy with the program; I think that they can sense that. (P9)

Similarly, P14, who equates burnout with "spillover" of family stress, described the need to separate the personal stress from impacting clients. After relating a story about the loss of a family member, he said: 
So you learn how to leave that at home, and not let it affect your work. But something as traumatic as that, it affects you tremendously. But you have to leave it at home; you can't take it to work with you. It's not the kids that I work with or their families' fault. (P14)

Even when participants are at the extreme level of burnout, an internal work ethic

propels some to keep providing a high level of care:

I was talking with somebody about that recently and I sat there and I told them, "You know what, I can't wait to find a new job. I'm tired of this job, I can't stand the people I work for." And I said, "And as much as I want to sit here and be lazy and do as little as I can to get through the day, it's not in my nature, it's not in my DNA. I'm constantly going above and beyond and trying to help them as much as I can." So, I do not feel my burnout has any effect on the quality of care that I deliver for the family and the kids. (P15)

Most participants, even though they also may try not to let burnout affect clients, did recognize an impact on client care.

Less tolerant/more directive. Participants talked about their interactions with clients and how their own level of stress may make them less tolerant and more directive with clients. For example, one responded, "Oh I'm sure it does. Probably the tolerance is not there, maybe not being as open to listen or work with them. Maybe being a bit more direct, maybe put them in an ultimatum type of situation instead of being open to work with them." (P4). Another participant was reluctant to think that burnout could have a direct impact on client outcomes but did recognize, despite her best efforts, that burnout could affect her interaction with clients:

Not in a good way, not in a good way. I try my best, my absolute best to not let that affect it, and I don't know if it affects me locking them up. But I think it could affect some of the interfacing between us. You know they can kind of tell that I'm stressed out because I might react to something a little bit more strongly than I normally would. You know as far as you can't do this. But I don't think that it is helpful for them by any stretch of the imagination, no. (P16)

Another participant recognized that, at the extreme, burned-out workers could take out their frustration on the people they are working with:

If people are burned out, it negatively affects the kids and the families we work with because if the officer is not $100 \%$ on their game, they can take it out on a family. They can take it out on a kid and that's not fair to the family or the kid. Even though they can come in and the parents can be an ass and the kid can be 
a jerk, they still don't deserve maybe being screamed at or yelled at or maybe treated negatively just because the officer's burned out or having a bad day. I mean, they still have to act professional. (P24)

Doing the bare minimum. Several participants used phrases like not putting "forth as much effort," "just put the minimum in," or "simply maintaining". As one participant put it "there's a basic minimum [you] would have to do just because you have to, you're still here and you have the cases but, my concern for the kids and the real reason why I'm here, I kind have lost sight of it, because I was more concerned about people above me." (P18) By just putting in the minimum level of effort, it means that clients "might not get as much attention as you would have wanted to give them"(P8) or that workers "maybe don't take as much care with each family, tend to kind of move them through without seeing the person. 'Gotta get this paperwork done, so I think that's how it affects them and it's not good." (P6).

Less attention may lead to reduced quality of care. Some participants gave examples of how doing the bare minimum might then affect the quality of care. Acknowledging that a high work load, combined with lack of caring, can lead to ineffective decisions, one participant described:

Not putting in real thought into my decisions when it was time to do a report...unfortunately [you] get to the point sometimes when you didn't care. You just had to get it done, because you had 6 more reports waiting. So, by all means it was not helping the client if I'm not into it, if I'm not putting some real thought and process into what my decisions were, what my recommendations were going to be to the judge, they certainly would not be getting necessarily the best service. (P1).

Divided attention can lead to less focus on the clients themselves: "If I'm worried about keeping all of my ducks in a row, I can't really listen to them and take into consideration their thoughts and concerns and needs as well." (P26). Another participant, echoing earlier sentiments on working hard to not let stress affect clients, described how a lack of attention to detail can lead to missing things.

If you're not careful, you could focus more on cutting your time with them and not dealing with their problems because you've got problems of your own to deal with. So you have to stop and focus. You have to prioritize on the kid more than 
the pile that's on your desk or the people that are waiting or you know; you'll get it done later on. ... you're not able to sit and focus on what is being said or how it's being said. You don't closely monitor the details, you just look at the general details and you miss things. (P10)

Another participant went on to link missing the details to client outcomes as well. "I think it keeps me from knowing what's going on with those kids, with them meeting their expectations, and then maybe even the extra things that are going on in their lives that could be affecting maybe why they're not getting something done. Or maybe why they are getting into further trouble." (P20)

\section{How do probation officers manage burnout?}

Limited strategies. One person reported having no strategies for managing burnout, saying, “Not really, that's always been a real weak spot for me. I don't think I am very good at taking care of myself." (P11). Another did not mention any specific strategies, but noticed that burnout was better when she got caught up on work demands: "It's just when I finally get caught up on everything and I'm able to spend a little bit more time, that's pretty much it."(P20). Similarly, another noticed less stress when the organization moved to electronic files, saying, "The stress is relieved by shoving everything into electronic form and getting it put away" (P10). For another person, burnout was relieved after a "reorganization of cases and caseloads and supervisors; it was just sort of, it happened that way. It wasn't like it was on purpose, you know what I mean?" (P18).

Seeking coworker and/or supervisor support. Many participants $(n=9)$ described social support from coworkers and supervisors as being active strategies for reducing burnout. Several mentioned being able to "vent" or "blow off steam;" for example, "I think what helps me relieve my burnout is what I did yesterday. I went to the other probation officers and vented. Then I moved on, because I've got 60 to 100 other kids I have to deal with and work with. And that's kind of what we all do - we vent to each other then move on to the next case."(P7).

Coworkers can also provide instrumental support. As P20 noted: 
I feel like I have some co-workers that would definitely help out, as I would with them, if they knew that I needed help. But like say, [if] I'm sick a day, the person who knows if I have appointments or not is my supervisor, and whether or not they need to be covered, and they're the ones who would be asking others to help with that.

A supervisor talked not only about the importance of providing support, but also advocating for staff, though sometimes that comes with a cost:

[State Agency] requirements, you know, you jump through hoops, you beg, you pray, and basically you better find the resources to help with burnout on your own because you ain't gonna get it anywhere else. You know, if you have the right office atmosphere, you've got each other. Hopefully you have a supervisor who is supportive; I try to be very supportive. And when my staff gets treated like dirt, I stand up for them, so I think that makes a difference. It certainly did when I was supervised, and I have been supervised. I do have a supervisor above me. That support makes a difference. And there is not a whole lot, there's not a whole lot. You have to draw from where you can. I try to take a walk frequently, try to commiserate with others who are doing the same work. Try to be a good advocate, but you have to be careful because if you talk too much, it's gonna cause political problems for the judge you work for and that's gonna come back and bite you. (P21).

Getting away. In addition to social support, nine participants described distancing themselves from work. One person talked about distancing in terms of setting boundaries: "I think maybe sometimes drawing boundaries. Some of our kids we can get pretty involved in, so that is pretty easy to do." (P23). Most distancing, however, involved taking time off of work for rejuvenation, for example, "you get a break, you get a few days, you get a holiday weekend and you can kinda bounce back."(P1). One participant described the need to leave the country for vacation, because he may be too accessible otherwise:

Vacation. I go away. I go out of the country for vacation every year. That's the only way I can get away. Because now, when I go out of the country, I turn my phone off and I don't have Internet. I don't have TV where I go. But if I'm around home having vacation, I still get the emails from my phone; I've been called in on my vacation. So the only way I can really, really just get away from it is to leave the country."(P24)

While vacations were a popular strategy, a few participants also described drawbacks to this strategy. Vacations do not relieve the workload: "[The] problem with taking a week off is you're right back where you started from" (P16). Or worse, "you have double the amount of work 
when you come back because you took off. It's not like anyone else picks up the slack. It's the kind of job that we work extra hard the two weeks that we go on vacation and the two weeks after we get back to make up for the time that we were gone. Nobody does it while we are gone." (P2). There is an added stress of the vacation itself, as highlighted in the following quote:

Or [laughing] thank God for vacations, but if you want to take one, you have to have all your reports done, not only for that week that you're gone .... So I stay busy, and then when you try to get two weeks' work into one, or even try to get ahead or move forward, it's very, very hard to do. So actually some of the most stressful times is [sic] getting ready to go on vacation because you keep asking yourself, "Am I gonna have this work done and be allowed to go?" And you're telling your wife, I don't know if I am gonna make it this time, blah blah blah and you have plane tickets" (P17).

The extreme form of distancing from work is to leave the position. One participant started by talking about vacations as a strategy, but she actually left her position as a probation officer to become a supervisor: "Well, I've been here for 18 years, so I haven't made a whole lot of changes, but I take lots of vacations. I think before, as a PO, I either needed to make a change or do something different, and that is when I applied to be a supervisor." (P4). Similarly, P7 said, "I guess if I was really burned out I would find a different job. I think for me, what I would do, and probably what you have to do as a probation officer, you need to disassociate yourself from the whole thing. Because otherwise it will drag you down because it's a tough job."

Enriched home life. Many participants described actively separating home life from work life. This is another form of getting away, but it also frequently involved supportive others (e.g., friends, spouses, family), activities, and hobbies. Below are a few different examples of enriching activities:

Tried to leave it at work. Talked about it with my spouse, talked about it with my supervisors and the director... I try to leave it at work, because I have other responsibilities and children at home. So when I go home I just focus on them and doing things with them. Whether it's going outside and playing, or playing games, or reading, or whatever it is that night. I just focus on them and what we are doing with my children. (P8)

Well, usually I try to do something creative. I have different projects that I like to do, reading, just anything that kind of takes your mind away from work. Do something a little for yourself. (P13) 
Uh, even though I've had this job for some time now, I try not to be jaded about things. I try not to take the job home with me, I have nice release mechanisms at home: playing guitar, reading, things like that. I've got some good friends. (P17)

Two probation offers mentioned exercise as a way to cope with burnout, and two mentioned alcohol: "Glass of wine helps" (P4), and another said jokingly, "Drink? No. (Laughs.) I guess for me, I don't take my work home with me. When I go home I focus on my own kids. I don't let my work consume my life. So then I try to keep them separated, so that [they don't] start interfering with each other. Just like I don't bring my home life to work." (P25).

Finally, one participant (P19) was notable for describing a very extensive regimen to prevent burnout, as he says he has never experienced burnout:

I am introspective and self-reflective. And with my training in psychology and cognitive therapy and behavior, I just think that the individual has control over how they see things and react to things. And I think that's really been a strength of mine to try to pass that on to people that I work with.

(Interviewer asks, "Is there anything else you do to avoid feeling burnout then?") Yea, I certainly know the importance of nutrition, eating good, sleeping good, exercising; all those help a person meet the challenges of the physical or psychological stresses of everyday life. My personal specialty when I was in grad school, I had to deal with, I studied stress, and I was trained in deep muscle relaxation. And there were other modes of relaxing. I could go back and tell you all about stress and what it does physiologically and psychologically, but that was an area of interest with me. Learn that you can't be stressed and relaxed at the same time. So, if you can learn to identify when you're stressed, there are measures that reduce stress and promote relaxation.

(Interviewer asks, "So it's more of stress management?") Yea. And foresight. At this point I have the advantage of saying I've been married the same time, 35 years. And to a great person, my wife... the best children... I am just super blessed, and it gives me more security in my everyday convictions of how family is important, how to treat people. But you gotta take care of yourself too.

\section{Discussion}

This is the first study we are aware of to delve into the experience of burnout for juvenile justice probation officers. It is clear that the work is stressful, with many competing demands. Self-reported burnout was common, with about a quarter of the sample reporting feeling burned out at the time of the interview. While there was a range of severity of the burnout experience, 
probation officers described the experience in very similar terms to Maslach's (Maslach, 1996; Maslach et al., 2001) conceptualization of being emotionally exhausted and overwhelmed, not caring or connecting to others, and not making a difference in work lives. This is notable given the open-ended, qualitative interview structure that officers' experiences map onto a quantitative self-report measure so well. Finally, while some saw burnout as a steady battle, many talked about periodic burnout, with "peaks and valleys" in the work experience.

Probation officers described needing to keep a "public image" that is separate from how they may really be feeling. Despite being stressed by work or family concerns, they try to keep those feelings away from their work with probation clients. This type of effort has been called "emotional labor" and has been widely studied in other areas of the service industry (Ashforth, 1993; Morris \& Feldman, 1996). Managing or trying to suppress emotions takes energy. Over time, this work is unsustainable and, as expected in the Conservation of Resources model of burnout (Hobfoll, 1989), depletion of resources can lead to disengagement and even turnover. Indeed, emotional labor has been associated with increased burnout in other occupational settings (Brotheridge \& Lee, 2002; Sliter, Chen, Withrow, \& Sliter, 2013).

Even while probation officers try hard not to let burnout affect their work, many recognized that burnout did have an impact - primarily in their relationships with clients. For example, probation officers may be intolerant or more directive with clients. Other research shows that clients and family members pick up on probation officer "exasperation" and experience some officers as being more punitive than others (Holloway, Brown, Suman, \& Aalsma, 2013). Probation officers in our study also described withdrawing from clients, similar to the idea of depersonalization in Maslach's conceptualiztion (Maslach, 1996). While focusing on the task and doing the bare minimum may be protective in reducing stress for the officer, this disengagement means that probation officers do not get to know the client as a person. Officers may not pay attention to clients and miss important details in their lives. Officers also may spend less time interacting with juveniles and engaging in activities that could be beneficial for youth 
on their caseload. Although we did not have access to client reports or objective outcomes, the perception of reduced quality of care as a result of burnout was clearly a concern of these officers. The finding that burnout affects their relationships with both youth on their caseload and the probationers' parents is particularly worrisome given the important role of the officer-youth relationship on successful outcomes among juvenile justice involved youth (Skeem \& Manchak, 2008). Similarly, a recent grounded theory of probation work described youth-officer relationships as "pivotal to probation success" (Schwalbe, 2012).

In terms of managing burnout, a few study participants had very limited strategies or passively happened upon things that helped reduce burnout (e.g., when the agency moved to electronic files, or when cases were reorganized). Most others described at least one or two strategies they used to actively manage stress and prevent or reduce burnout. Vacation was a popular choice, which came with its own stressors. For one participant, vacations only worked to relieve burnout if he left the country entirely - not a very practical strategy for most people. Two other popular strategies were pursuing social support in the workplace and developing enriching homelives with rewarding activities, supplemented by social support from family and friends. In the broader burnout literature, social support is a key factor in reducing burnout (Halbesleben, 2006). While most study participants had something they did to manage burnout, only one person had a very extensive burnout prevention plan, which appeared effective for him. Notably, the strategies included many elements of effective burnout interventions that build on a multimodal approach to reducing stress: relaxation exercises, cognitive strategies, and emphasizing physical health and nutrition (Awa, Plaumann, \& Walter, 2010; Morse et al., 2012).

One clear implication of our findings is that interventions could be useful for addressing burnout in probation officers. In addition to the stressors of the work itself (e.g., Pitts, 2007), officers described a great deal of emotional labor in keeping their stress from affecting the clients that they work with. Over time, this type of effort could actually increase burnout, and interventions could be helpful in stopping a cycle of increased exhaustion, disconnection, and 
withdrawal. The finding that most officers had a limited repertoire of strategies for managing burnout and stress, combined with the potential impact on probation officers, also points to the need for intervention.

Some suggestions for intervention approaches come directly from the officers in this study. Interventions could target the individual, to help probation officers build effective stress management techniques focused on reducing emotional labor and exhaustion. A variety of techniques have been tried in other fields, including providing educational information, cognitive restructuring, progressive muscle relaxation, and social skills training (Awa, Plaumann, \& Walter, 2010; Morse et al., 2012; Murphy, 1996) However, a recent study of burnout in corrections centers suggests that multiple approaches may be needed, beyond teaching adaptive coping responses (Gould, Watson, Price, and Valliant, 2013). Given the salience of social support in this study, interventions could specifically create opportunities for officers to help each other. As noted in a recent study of officers in a juvenile corrections facility (Lambert et al., 2010), different types of social support may impact different aspects of burnout. In our study, officers also mentioned supervisors as a source of support. Interventions could be developed to help supervisors learn effective strategies for better supporting officers in their departments. Even interventions focusing on increasing trust between officers and their supervisors may be beneficial (Lambert et al., 2012). Organizational interventions may also be helpful, to address sources of burnout (e.g., reducing workload, organizational climate).

This study was meant to provide a deeper understanding of the experience of burnout from a small number of participants. Although we did randomly select particpants and covered both urban and rural areas, we were limited to one state. It is possible that our probation departments differ systematically from other settings, which could limit the generalizbility of our findings. The study itself, though, does not appear to be limited by a biased sample. In the quantiative portion of this study, 95\% of probation officers approached agreed to participate 
(Author, under review), and 65\% of those were willing to be interviewed. These high rates also suggest strong interest among participants for discussing burnout.

Given the lack of prior research in this area, our study opens the door to a rich area of future work in exploring how to effectively prevent burnout and turnover in this high-stress field. The possible effects of burnout on the clients served, as reported here, also suggest important next steps in this line of work. For example, it may be fruitful to study how burnout impacts probation officer relationships with clients and their juvenile justice outcomes. Lastly, there continues to be great interest in providing evidence-based care for youth in juvenile justice. For instance, motivational interviewing and cognitive behavioral techniques have been adapted for probation officers (Hartzler \& Espinosa, 2011; Landenberger \& Lipsey, 2005). Both motivational interviewing and cognitive behavioral techniques warrant intensive training, which can be costly. Clearly, when juvenile probation officers are burned out and contemplating a new occupation, they are less effective in providing evidence-based care, and if a juvenile probation officer leaves for a different occupation, a new staff member needs to be hired and trained, adding cost. Thus, limiting burnout among juvenile probation officers should be considered as a preventative measure to possibly improve juvenile probation practices and reduce staff turnover. 


\section{References}

Ashforth, B. E. (1993). Emotional labor in service roles: The influence of identity. Academy of Management Review, 18(1), 88-115.

Author (under review). Job-related burnout and its correlates among juvenile probation officers.

Awa, W. L., Plaumann, M., \& Walter, U. (2010). Burnout prevention: a review of intervention programs. Patient Education and Counseling, 78(2), 184-190.

Brotheridge, C. M., \& Lee, R. T. (2002). Testing a conservation of resources model of the dynamics of emotional labor. Journal of occupational health psychology, 7(1), 57.

Clear, T. R., \& Latessa, E. J. (1993). Probation officers' roles in intensive supervision: Surveillance versus treatment. Justice Quarterly, 10(3), 441-462.

Gayman, M. D., \& Bradley, M. S. (2012). Organizational climate, work stress, and depressive symptoms among probation and parole officers. Criminal Justice Studies, 26(3), 326346.

Gould, D. D., Watson, S. L., Price, S. R., \& Valliant, P. M. (2013). The relationship between burnout and coping in adult and young offender center correctional officers: An exploratory investigation. Psychological Services, 10(1), 37.

Halbesleben, J. R. (2006). Sources of social support and burnout: a meta-analytic test of the conservation of resources model. Journal of Applied Psychology, 91(5), 1134.

Hartzler, B., \& Espinosa, E. M. (2011). Moving criminal justice organizations toward adoption of evidence-based practice via advanced workshop training in motivational interviewing: A research Note. Criminal Justice Policy Review, 22(2), 235-253.

Hobfoll, S. E. (1989). Conservation of resources: A new attempt at conceptualizing stress. American Psychologist, 44(3), 513-524.

Holloway, E. D., Brown, J. R., Suman, P. D., \& Aalsma, M. C. (2013). A qualitative examination of juvenile probation officers as gateway providers to mental health care. Criminal Justice Policy Review, 24(3), 370-392. 
Lambert, E. G., Altheimer, I., \& Hogan, N. L. (2010). Exploring the relationship between social support and job burnout among correctional staff. Criminal justice and behavior, 37(11), 1217-1236.

Lambert, E. G., Hogan, N. L., Barton-Bellessa, S. M., \& Jiang, S. (2012). Examining the relationship between supervisor and management trust and job burnout among correctional staff. Criminal Justice and Behavior, 39(7), 938-957.

Landenberger, N. A., \& Lipsey, M. W. (2005). The positive effects of cognitive-behavioral programs for offenders: A meta-analysis of factors associated with effective treatment. Journal of Experimental Criminology, 1(4), 451-476.

Leiter, M. P., \& Schaufeli, W. B. (1996). Consistency of the burnout construct across occupations. Anxiety, Stress \& Coping: An International Journal, 9(3), 229-243.

Lewis, K. R., Lewis, L. S., \& Garby, T. M. (2013). Surviving the trenches: The personal impact of the job on probation officers. American Journal of Criminal Justice, 38(1), 67-84.

Maslach, C., Jackson, S. E., Leiter, M. P. (1996). Maslach Burnout Inventory Manual (3 ed.). Palo Alto, California: Consulting Psychologists Press.

Maslach, C., Schaufeli, W. B., \& Leiter, M. P. (2001). Job burnout. Annual Review of Psychology, 52, 397-422.

Morris, J. A., \& Feldman, D. C. (1996). The dimensions, antecedents, and consequences of emotional labor. Academy of Management Review, 21(4), 986-1010.

Morse, G., Salyers, M., Rollins, A., Monroe-DeVita, M., \& Pfahler, C. (2012). Burnout in Mental Health Services: A Review of the Problem and Its Remediation. Administration and Policy in Mental Health and Mental Health Services Research, 39(5), 341-352.

Murphy LR. Stress management in work settings: a critical review of the health effects. American Journal Of Health Promotion: AJHP. 1996;11(2):112-135. 
Paparozzi, M. A., \& Gendreau, P. (2005). An intensive supervision program that worked: Service delivery, professional orientation, and organizational supportiveness. The Prison Journal, 85(4), 445-466.

Pitts, W. J. (2007). Educational competency as an indicator of occupational stress for probation and parole officers. American Journal of Criminal Justice, 32(1-2), 57-73.

Puzzanchera, C., Adams, B., \& Hockenberry, S. (2012). Juvenile court statistics 2009. Pittsburgh, PA: National Center for Juvenile Justice.

Rapp-Paglicci, L. A. (2004). Juvenile probation officers: Safe and sound? Stress, Trauma, and Crisis, 7(1), 17-28.

Schwalbe, C. S. (2012). Toward an integrated theory of probation. Criminal Justice and Behavior, 39(2), 185-201.

Schwalbe, C. S., \& Maschi, T. (2009). Investigating probation strategies with juvenile offenders: The influence of officers' attitudes and youth characteristics. Law and Human Behavior, 33(5), 357-367.

Skeem, J. L., \& Manchak, S. (2008). Back to the future: from Klockars' model of effective supervision to evidence-based practice in probation. Journal of Offender Rehabilitation, 47(3), 220-247.

Sliter, M., Chen, Y., Withrow, S., \& Sliter, K. (2013). Older and (emotionally) smarter? Emotional intelligence as a mediator in the relationship between age and emotional labor strategies in service employees. Experimental Aging Research, 39(4), 466-479.

Steiner, B., Purkiss, M., Kifer, M., Roberts, E., \& Hemmens, C. (2004). Legally prescribed functions of adult and juvenile probation officers. Journal of Offender Rehabilitation, 39(4), 47-67.

Whitehead, J. T. (1985). Job burnout in probation and parole: Its extent and intervention implications. Criminal Justice and Behavior, 12(1), 91-110. 
Whitehead, J. T. (1987). Probation officer job burnout: A test of two theories. Journal of Criminal Justice, 15(1), 1-16. 